\title{
Special Feature: Eight Orbitals of Inquiry: Reconceptualizing Narrative Methods in Education Research
}

\author{
Leah Fowler \\ University of Lethbridge
}

Eight orbitals of narrative analysis are presented as a long term interest in autobiographical inquiry, narrative methodology, and curriculum studies in education research. This is also an experiment in thought and play with technology in the journal, in education, in hopes that others in the scholarly and teaching communities will read, think and participate in other conversations about the reconceptualization, reconstruction, and use of narrative analysis, curriculum theory and pedagogic practice in education and research.

See Leah's website: http://people.uleth.ca/ leah.fowler/Narrativefowler/Welcome.html 